REVIEW

\title{
Emergency department response to the deliberate release of biological agents
}

\section{J E Ollerton}

Emerg Med J 2004;21:5-8

Bioterrorism is the use of biological agents outside the arena of war. Its purpose is to disrupt civilian life. This article investigates the role of the emergency department in the event of an act of bioterrorism.

B iological warfare (BW) is an effective method to inflict death and disease across large populations. It is the intentional spread of disease through the dissemination of bacteria, viruses, or toxins. The war time aim is to cause high morbidity, mortality, and generalised suffering in order to sap the morale of troops, soak up the support services in their evacuation and care, and hence drain the fighting force. The associated psychological impact of BW is a key element in the threat of terrorist attacks using biological agents. Bioterrorism constitutes the use of biological agents outside the arena of declared war in order to inflict casualties and to create fear, so disrupting daily civilian life. Motivation is usually political and civilians frequently targeted. Bioterrorism has been recently pushed into the public domain by events in the United States of America after September 11th. Before that it has traditionally been a subject of the military world. It is indiscriminate causing harm in all those who come in contact with it unprotected. Only small numbers of people need to be affected to initiate enormous repercussions making bioterrorism a very effective tool.

\section{HISTORY}

BW is not a new concept. One of the first recorded uses of BW dates back to the Great Plague of the 14th century, which killed a third of the population of Europe. ${ }^{1}$ A Mongol army lay siege to a Genoan trading post in the Crimea. When the Plague broke out among their own troops they took to catapulting the infected corpses over the enemy walls spreading the disease and consequently defeating the enemy. Any remaining Genoans fled via Naples to Genoa spreading the Plague as they went with devastating effect. More recently anthrax was disseminated in the United States of America using contaminated letters through the postal services-a crude but effective method of creating terror despite only a comparatively ineffective spread of disease.

Several international agreements have outlawed the use of biological agents. The Hague Convention in 1899 was one of the first followed by the Geneva Protocol of 1925 and most recently Department of Trauma Liverpool Hospital Sydney, NSW 1871 (......................
Correspondence to: the Biological Weapons Convention in 1972 under which we still work today. ${ }^{2}$

\section{THE THREAT}

So which agents constitute the main threat? Smallpox, anthrax, the Plague, tularaemia, and viral haemorrhagic fevers are all known to be available around the world in forms able to be produced and disseminated. Biotoxins are bacterial byproducts or naturally occurring chemicals. They do not replicate within the host and are non-infective. Examples include Clostridium botulinum neurotoxin, Staphylococcal enterotoxin B, and ricin. The American Centers for Disease Control and Prevention (CDC) have targeted several planning and surveillance measures of importance in the response to bioterrorism. ${ }^{3}$ To focus these issues the potential biological agents had to be first identified and their risk prioritised. A forum of national experts was convened to classify biological agents to provide a framework for an objective risk analysis for any given agent. The agents were evaluated in four key areas and a rating given to allow assignment into to groups A, B or C. The four areas considered were (1) the public health impact based on illness and death; (2) delivery potential to large populations based on stability of the agent, ability to mass produce and distribute a virulent agent, and potential for person to person transmission of the agent; (3) public perception as related to public fear and potential civil disruption: and (4) special public health preparedness needs based on stockpile requirements, increased surveillance, or diagnostic needs. ${ }^{4}$ The biological agents having the greatest potential for adverse public health impact have been categorised group A. These have the greatest potential for mass casualties and require the most broad based public health preparedness efforts. Agents not believed to currently present a high bioterrorism threat were placed in category C (table 1$)$.

The potential for the development of increasingly specialised agents is recognised. Chimaeras are the offspring of a cocktail of diseases that form a "super" infectious agent. Gene manipulation has provided the technology to convert a simple virus to a lethal one resistant to vaccines and antibiotics. Recent Australian experiments have demonstrated that by adding certain genes to the viral genome it is possible to create a

Abbreviations: BW, biological warfare; PPE, personal protective equipment 
Table 1 Biological agent categories for public health preparedness

\begin{tabular}{ll}
\hline Biological agent (s) & Disease \\
\hline Category A & Smallpox \\
Variola major & $\begin{array}{l}\text { Anthrax } \\
\text { Plague }\end{array}$ \\
Yacillus anthracis & Botulism \\
Clostridium botulinum & Tularaemia \\
Francisella tularensis & Viral haemorrhagic fevers \\
Filoviruses and arenaviruses (for example, Ebola virus and Lassa virus) & \\
Category B & Q Fever \\
Coxiella burnetii & Brucellosis \\
Brucella spp & Glanders \\
Burkholderia mallei & Melioidosis \\
Burkholderia pseudomallei & Encephalitis \\
Alphaviruses (VEE, EEE, WEE) & Typhus fever \\
Rickettsia prowazekii & Toxic syndromes \\
Toxins (for example, ricin, staphylococcal enterotoxin B) & Psittacosis \\
Clamydia psittaci & \\
Food safety threats (for example, Salmoella spp, E coli 0157:H7) & \\
Water safety threats (for example, Cryptosporidium parvum) & \\
Category C & \\
Emerging threat agents (for example, Hantavirus, Nipah virus) & \\
\hline VEE, Venezuelan equine; EEE, Eastern equine; WEE, Western equine encephalomyelitis. \\
\hline
\end{tabular}

resistant virus potentially able to influence the human immune system with overwhelming effects. ${ }^{5}$

\section{TRANSMISSION AND PREVENTION}

"Deliberate release" refers to any intentional spread of biological (or chemical) agent. This may be overt-that is, clearly identifiable either because of prior warning or obvious dissemination of a suspicious substance. Release may otherwise be covert with concealed release of a biological agent when the first evidence may be the identification of victims.

Food, water, or insects are potential vectors with aerosol dissemination as the most effective means of spread over large areas. It is not inconceivable for an infected terrorist to personally deliver a highly infectious agent to key areas of society, market places, theatres, airports, and so on where large volumes of people congregate and ensure the onward dissemination.

Total protection against all potential BW agents is practically impossible. Considerations include the use of personal protective clothing, vaccinations, antidotes, and prophylactic medications. Full personnel protective equipment (PPE) constitutes sealed clothing, head cover, gloves, boots, and breathing apparatus. Commonly used by the military and the fire service, use of full PPE is cumbersome, inconvenient for personal hygiene and feeding, and very hot to wear. It also limits vision, communication, and physical activity. Areas of high contamination such as at the scene of an incident will need use of full PPE, the Department of Health have recommended ensembles from Respirex International Ltd. ${ }^{6}$ For the majority of infectious cases received in hospitals standard universal precautions provide sufficient protection. This includes gown, cap, overshoes, gloves and eye shields with face mask, in some circumstances a high efficiency face mask (dust/mite mask) ${ }^{7}$ will be recommended. Specialist advice must be taken. Department of Health guidelines to the NHS Trusts detail the equipment required by those personnel receiving potentially contaminated patients. ${ }^{68}$ Further information is available from the Public Health Laboratory Service and Department of Health web sites (http://www.phls.org.uk and http://www.doh. gov.uk)

\section{RECOGNITION}

Symptomatology will be delayed for the incubation period, which may be weeks from the time of the inoculation. This permits optimal spread and establishment of the agent across a population, perhaps enabling a contagious agent to spread before a diagnosis is reached and even before an evolving epidemic is recognised.

The general practitioner and emergency medicine physician are likely to be the first to recognise an outbreak of unusual disease. A high level of suspicion is needed in order to consider a BW agent as a cause. Early consultation with infectious disease specialists and notification of infections to the consultant for communicable disease control (CCDC) will permit recognition of patterns of illness. The CCDC and the Communicable Disease Surveillance Centre (CDSC) are now a part of the Health Protection Agency (CDSC-HPA). The CCDC and regional public health physicians will initiate the infection contact tracing and coordinate the response in conjunction with health authorities. The Health Protection Agency is a new national organisation dedicated to reducing the impact of infectious disease, chemical hazards, poisons, and radiological hazards. It brings together the expertise of the public health, communicable disease, infection control, and emergency planning departments. The Emergency Planning Coordination Unit (EPCU) liaises with government departments on matters related to the contingency planning for emergency incidents so will be closely involved.

\section{ACTION}

A check list of actions for lead hospital clinicians dealing with cases of unusual illness is available. ${ }^{8}$ A record of all parties notified and actions taken must be kept in the emergency department, similarly all staff who come in contact with affected patient(s) should also be recorded and their level of exposure logged. The Department of Health web site (http:// www.doh.gov.uk) provides further information on the management of major incidents and response to the deliberate release of biological agents.

If patients suspected of exposure to a biological agent present to the emergency department then the local hospital policy for such an event must be activated. If no such policy exists the Department of Health has provided guidance. ${ }^{8-10}$ Immediate notification of key personnel (fig 1) will start a cascade of responses locally, regionally or nationally depending upon the incident. The initial priority is consideration of personal safety to staff with prevention of contamination of the hospital complex and personnel. Not all biological agents are infectious but in the early stages of any outbreak it is 


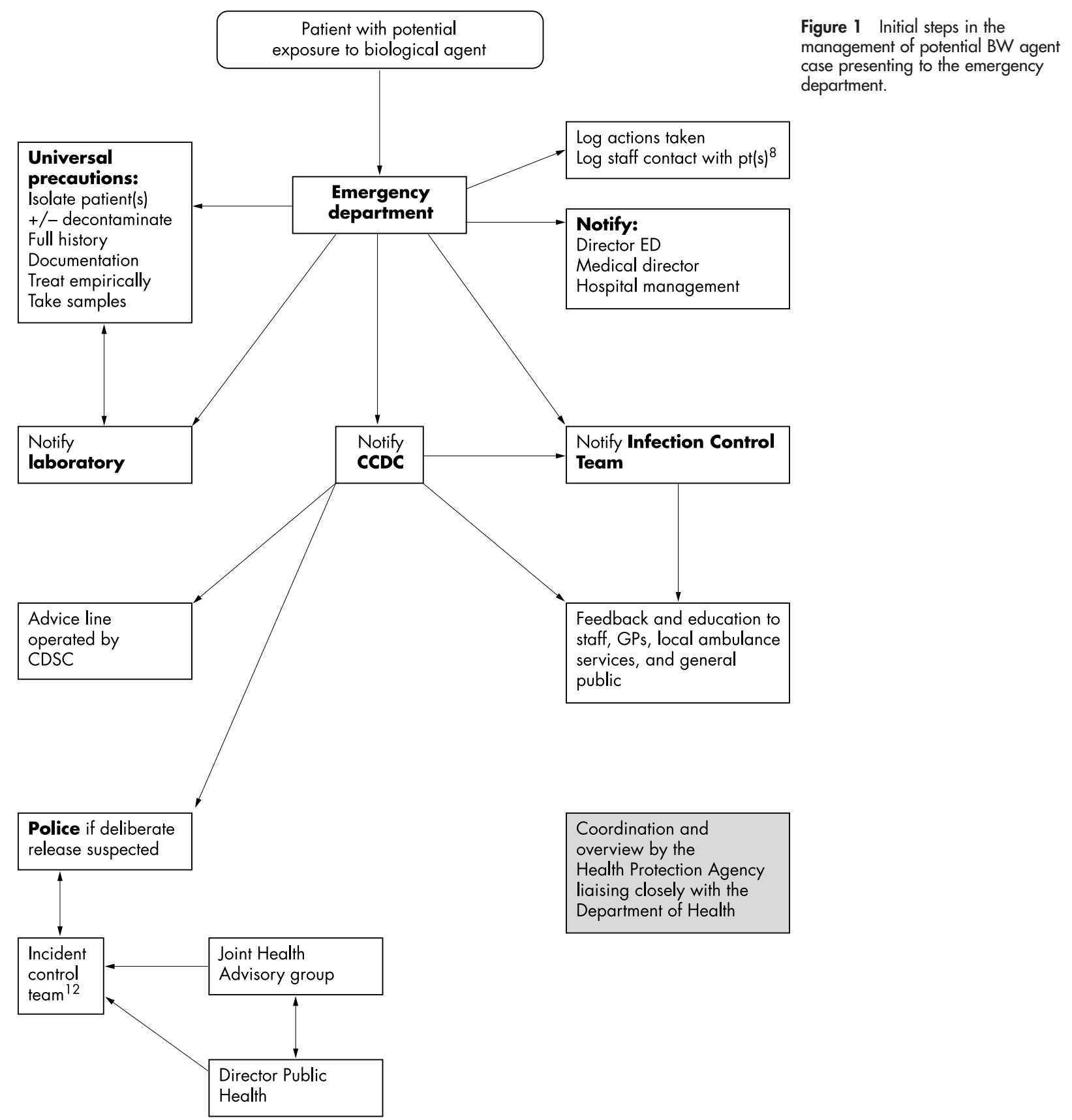

probable that the agent will not have been identified so all protective mechanisms must be in place.

A sheltered area must be declared "dirty" for the initial assessment and decontamination of patients when appropriate. Ideally this will be away from the hospital to prevent contamination of the medical facility. This area must be clearly cordoned and security may be required to reinforce the area depending on the numbers of people involved. Medical assistance may be required within this dirty area when large numbers of casualties are affected for the initial triage of patients or when life threatening conditions coincide. This is more likely if there has been overt release of an agent and associated trauma for example when deliberate release of the agent is associated with an explosive device. Covert release is likely to result in potential contamination of the initial clinical staff attending the patient who must then be recognised as "exposed" and treated as such.
PPE must be available and worn by all staff, the patients must be decontaminated in the designated areas and antidotes administered when applicable. In the early stages of an outbreak it is unlikely patients will be recognised as the start of a potential epidemic so little if any of the above will be done. Patients will present to a variety of medical facilities over a period of time. Physicians may notice a pattern of disease presenting, diagnosis may take time and treatment will initially be empirical.

Detailed history taking is imperative with check lists available to ensure maximal information is acquired. ${ }^{8} \mathrm{~A}$ comprehensive guide on presenting features of unusual illnesses is available from the Public Health Laboratory Service $^{8}$ and the Health Protection Agency (http://www. hpa.org.uk/infections/topics_az/deliberate_release/unknown/ unusual_illness.pdf). All laboratory samples taken must be labelled "high risk" as must products from cleaning and waste disposal. Isolation of patients may be necessary, this 
may be on an individual patient basis or involve whole wards. Stockpiles of antibiotics are held in case of outbreaks of disease; these can be mobilised quickly in the event of a deliberate release of biological agent. An example of this requirement for overt anthrax release is demonstrated on the Department of Health web site (http://www.doh.gov.uk/epcu/ cbr/biol/anthovdel.htm). Liaison with the infectious diseases team is emphasised.

\section{MEDIA}

Media news broadcasts need to show continuous updates of the situation with reliable education of the general public in an attempt to prevent mass panic and the subsequent overwhelming of medical facilities. A dedicated press officer should give all medical briefings in liaison with other health authority agencies involved.

\section{DECONTAMINATION}

When a contaminated patient arrives at an emergency department they must not be allowed to infect the hospital. The need for decontamination will be decided by the first responder until further advice is available. Decontamination will not always be appropriate, for example when infection is spread by ingestion. Such cases may be managed more appropriately by isolation to prevent ongoing spread. The Fire Service provides mobile decontamination units that should be used to decontaminate patients prehospital whenever possible. The Home Office Strategic National Guideline on decontamination $^{11}$ is available at on the Department of Health web site (http://www.doh.gov.uk/epcu/cbr/cbrpdf/ cbrn2003.pdf).

Initial decontamination usually depends on removing all clothing and thorough washing with soap and water. A "rinse, wipe, rinse" method using high volume, low pressure water and detergent is recommended; hypothermia is a significant risk particularly in the very young and very old.

Triage and resuscitation of life threatening injuries may take initial priority and facilities to enable this must be made within the "dirty" area of the patient reception. Strict segregation of clean and dirty areas, equipment and staff must be maintained. Hospital facilities need to be checked and supplemented to ensure they reach adequate standards for both biological and chemical decontamination. ${ }^{6-11}$

\section{SUMMARY}

The emergency department will have a pivotal role in the event of an outbreak of unusual illness attributed to deliberate release of a $\mathrm{BW}$ agent. By recognition of the potential risks and protection of the medical facility from contamination a smooth process of infection isolation, identification and management can be initiated. Communication between staff, departments, emergency services, and government agencies is the key to preventing panic and achieving maximal control. Feedback and education of staff and the public will facilitate the process.

The outlook would appear pretty dismal if such agents were used against unsuspecting and unprepared populations but recent events across the world have precipitated much work to allow full preparation by all those involved. As "front line" physicians in the emergency department we must maintain a high level of suspicion for unusual outbreaks of disease, we must educate ourselves on the management of these key conditions, and ensure our hospitals and staff are aware of the procedures in place to cope with potential victims of BW.

\section{REFERENCES}

1 Lederberg J. Germs as weapons: a grim history. A lecture by Dr J Lederberg, 27 Oct 1999 at Weill Medical College of Cornell, Manhattan. Summarised by Felicia Narvaez 4 Nov 1999 (http://www.news.cornell.edu/chronicle/99/ 11.4.99/bio_warfare.html).

2 Biological Weapons Convention 1972. Summary available at http:// www.fas.org/nuke/control/bwc/text/bwc.htm

3 Centers for Disease Control and Prevention. Biological and chemical terrorism: strategic plan for preparedness and response. Recommendations of the CDC Strategic Planning Workgroup 2000. MMWR Morb Mortal Wkly Rep 2000;49:1-14.

4 Rotz LD, Khan AS, Lillibridge SR, et al. Report summary. Public health assessment of potential biological terrorism agents. Emerg Infect Dis 2002;8:1-11, (http://www.cdc.gov/ncidod/EID/vol8no2/01-0164.htm).

5 Jackson RJ, Ramsay AJ, Christensen CD, et al. Expression of mouse interleukin-4 by a recombinant Ectromelia virus suppresses cytolytic lymphocyte responses and overcomes genetic resistance to Mousepox. J Virol 2001;75:1205-10

6 Mobile Decontamination Facilities and Personal Protective Equipment Department of Health letter to Chief Executives of NHS Trusts dated 22 Oc 2002 (http://www.doh.gov.uk/publications/index.html).

7 The Interdepartmental Working Group on Tuberculosis. The prevention and control of tuberculosis in the United Kingdom. London: Department of Health, the Scottish Office, the Welsh Office, September 1998.

8 PHLS. Initial investigation and management of outbreaks and incidents of unusual illness. A guide for hospital clinicians. PHLS and Chemical Incident Response Service, 2002. (http://www.phls.org.uk).

9 Department of Health. Pre-hospital chemical and biological incident response. A briefing document by the Department of Health dated 23 Oct 2001 (http://www.doh.gov.uk/epcu/cbr/cbrpdf/prehosp.pdf).

10 Department of Health. Hospital chemical incident response-practical advice. From the Department of Health dated 28 Sep 2001 (http://www.doh.gov.uk/ epcu/cbr/cbrpdf/hospcir.pdf).

11 Department of Health. The decontamination of people exposed to chemical, biological, radiological or nuclear (CBRN) substances or material: Strategic National Guideline. The Home Office Feb 2003. (http://www.doh.gov.uk/ epcu/cbr/cbrpdf/cbrn2003.pdf).

12 Department of Health and NHS Executive. Deliberate release of biological and chemical agents-guidance to help plan the Health Service response. London: Department of Health, March 2000. 